\title{
HENRIQUE DA ROCHA LIMA E A DESCOBERTA DA "RICKETTSIA PROWAZEKI" $\left({ }^{\star}\right)$.
}

Valendo-se de material procedente de doentes de tifo exantemático, durante a ocorrência duma epidemia dêsse morbo na Tunísia (África do Norte), na primavera e verão do ano de 1909, conseguiu Charles Nicolle, antigo discípulo de Pasteur, e então diretor do Instituto Pasteur de Tunes, realizar notáveis experimentações, mediante as quais comprovou, pela vez primeira no mundo, a passagem do virus daquela doença, do homem ao chimpanzé e ao macaco chinês (bonnet chinois dos franceses), desencadeando nestoutros quadros mórbidos semelhantes à infecção humana. Logo a seguir, evidenciou êsse pesquisador, em colaboração com C. Comte e E. Conseil, que a transmissão natural do germe em análise se dava por intermédio do piolho do corpo (Pediculus humanus). Tais conquistas científicas foram comunicadas, sem perda de tempo, à Academia das Ciências de Paris, e estampadas em notas prévias nos Comptes Rendus desta instituição ("Recherches expérimentales sur le Typhus exanthématique, entreprises à l'Institut Pasteur de Tunis, pendant l'année 1909" (1).

Prosseguindo nesses estudos experimentais durante anos consecutivos, novas descobertas praticou Nicolle, entre outras a sensibilidade da cobaia ao virus em aprêço e as infecções inaparentes dêsse animal de laboratório (2) .

Ao lado, porém, de tais fatos fundamentais incontestáveis por êle estabelecidos, foi induzido Nicolle, mercê duma experiência pouco convincente, a um falso caminho quanto à natureza do agente etiológico do tifo exantemático, admitindo-o como elemento filtrável e invisível ao microscópio.

"il est permis d'admettre qu'il s'agit d'un microbe invisible et filtrant; une de nos expériences de l'an passé ne comporte pas d'autre conclusion" (3).

(*). - Conferência pronunciada perante o III Congresso Pan-Americano e IV Brasileiro de História da Medicina, reunidos no Río de Janeiro, GB, Brasil, na sessāo'de 2 de dezembro de 1965.

(1). - Annales de l'Institut Pasteur, 24, n.o 4, Avril 1910: 243-275.

(2). - Ibidem, 26 n. 0 , Mai 1912: 348.

(3) - Ibídem, 26, n.o 4, Avril 1912: 264 
Na mesma ocasião em que Nicolle efetuava seus estudos na Tunísia, dois norte-americanos, Howard T. Ricketts e Russell $M$. Wilder, procediam a investigações sôbre o tifo exantemático no México. Convencidos, por experiências pessoais, da não filtrabilidade do virus exantemático e louvados no conceito da transmissão da doença pelos piolhos humanos, procuraram lobrigar no tubo digestivo de tais insetos os germes causadores. E chegaram a verificar a presença de certos corpúsculos em forma de diplo-bacilos, proliferando não só no conteúdo intestinal de piolhos infetados com sangue de acometidos pela doença, mas também observados (embora em menor número) em animais testemunhas indenes. Não obstante afirmarem haver igualmente avistado, ao microscópio, no sangue de doentes, alguns escassos elementos com configuração idêntica à daqueles corpúsculos, concluíram Ricketts e Wilder de maneira assás duvidosa quanto à possível ação etiológica de tais formações, apregoando expressamente:

"It is clear in our minds that the grounds are not sufficient for claiming an etiologic rôle on the part of the organism described, yet the conditions under which they are found, together with theoretical argument presented above, appear to demand that they be taken somewhat seriously and subjected to further study in their relationship to typhus" (4).

Mais adiante, ou seja no ano de 1914, Edm. Sergent, H. Folley e C. Vialatte, do Instituto Pasteur da Argélia (Africa do Norte), tendo tido oportunidade de estudar material de tifo exantemático de duas epidemias diferentes (Beni-Ounif-deFiguig e Mouzaiaville'), comunicavam à Sociedade de Biologia de Paris (sessão de 13 de junho) o achado de corpúsculos idênticos aos observados por Ricketts e Wilder, em esfregaços de piolhos retirados do corpo de doentes, acentuando que só haviam encontrado tais formas em insetos infectados e nunca em animais testemunhas (piolhos sãos). Como conclusão, afirmaram os três autores em aprêço:

"Si ces coccobacilles ne constituent pas le virus même du typhus exanthématique, on peut supposer que ce sont, comme c'est le cas pour plusieurs Pasteurella, des microbes "témoins" qui "accompagneraient" le véritable agent infectieux invisible" ("Sur des formes microbiennes

(4). - "The etfology of the typhus fever (tabardillo) of Mexico City". The Journal of American Medical Association, 54, n.0 17, April 22, 1910: 1375. 
abondantes dans le corps de poux infectés par le typhus exanthématique, et toujours absentes dans les poux témoins, non typhiques" (5).

Era, pois, de absoluta incerteza a situação de tais microrganismos na produção do tifo exantemático quando $\mathrm{H}$. da Rocha Lima e S. Prowazek, ambos chefes de serviço do Tropeninstitut de Hamburgo, foram comissionados pelo Govêrno Imperial Alemão para estudar violenta epidemia do morbo, irrompida num campo de prisioneiros russos, procedentes da grande batalha de Tannenberg, na qual o Feld-Mareschal von Hindenburg acabara de aniquilar os exércitos do Czar Nicolau II, afogando-os nos Lagos Mazurianos. Kottbus, a pequena cidade alemã, próxima a Berlim, foi o palco dessa trágica ocorrência: 7.000 dos 10.000 prisioneiros de guerra ali acantonados foram vítimas do tifo exantemático. Rocha Lima para lá se dirigiu em dezembro de 1914, em condições precárias de estudo, inteiramente desprovido de material adeqüado, isto é, de animais de laboratório para as inoculações imprescindíveis. Limitou-se, pois, de início, a pesquisar os elementos transmissores (piolhos) em preparações a fresco e coradas pelo Giemsa. Logo de saída deparou nos piolhos as formações já consignadas por Ricketts e Wilder e por Sergent e seus colaboradores, independentemente de ter tido antes ciência delas. Ficou, porém, na mesma situação de dúvida em que todos haviam permanecido. Quinze dias depois de estar em Kottbus, chega lá S. Prowazek, que passou a encarregar-se dos exames a fresco do conteúdo intestinal dos piolhos. Mantêm-se os dois pesquisadores em atitude de franca reserva em face do observado até então, mais descrentes do que crentes de terem diante de si a chave do problema, isto é, o verdadeiro agente etiológico da doença. Pouco depois de chegado a Kottbus, contamina-se Prowazek, adoece e falece a 17 de fevereiro de 1915. Rocha Lima entra a executar as tarefas que competiam ao desditoso companheiro. Também adoece logo em seguida, passa muito mal, mas consegue escapar com vida. A hidra do mal exantemático não poupa os que pretendem devassar-lhe os mistérios. E' longa a lista dos que tombaram no perigoso afã de conhecerlhe os segredos, figurando entre muitos outros nomes os de Ricketts, Prowazek, Lemos Monteiro, etc. Convalescente, volta Rocha Lima para Hamburgo, levando consigo precioso acervo

(5). - Comptes Rendus Hebđomadaires de la société de Biologie, séance da 13 Juin 1914, T. LXXVII: 103, Parts, P. et A. Davy, Imprimeurs. 
para estudo, colhido em Kottbus. E, na quietude de seu laboratório do Tropeninstitut, passa a reexaminar os seus piolhos. Nesta altura um fator nôvo vem em seu auxílio. Hilda Sikora, a excelente biologista do Tropeninstitut encarregada de estudar a biologia dos piolhos, tão mal conhecida até então, aperfeiçoa a técnica de lidar com êles. Constrói engenhosa gaiola para mantê-los em cativeiro, sem risco para os observadores, com dispositivo para poder alimentá-los sugando sangue humano ou de animais através duma abertura protegida por determinada espécie de gaze, de malhas suficientes para permitir a sucção, sem possibilidade, todavia, de evasão. Entretanto, como contribuição original e mais valiosa ainda dessa colaborado$\mathrm{ra}$, avulta o aperfeiçoamento da técnica de cortar piolhos. Graças a isso, pôde enfim Rocha Lima analisar, em cortes seriados, o conteúdo das células epiteliais do tubo digestivo de tais insetos, no interior das quais veio a fazer sensacional e fundamental descoberta. Assim é que percebeu, parasitando tais células, de maneira característica, nos animais infectados por tifo exantemático, aquêles mesmos corpúsculos encontrados na luz do canal alimentar e observou extraordinária multiplicação dêles intracelularmente, a formarem saliências tumorais que se vinham a romper dentro do intestino, parasitos êsses com a mesma morfologia dos diplo-bacilos encontrados por Ricketts e Wilder, e por Sergent e outros. Aprofundando tais estudos, conseguiu Rocha Lima diferençar tais elementos intracelulares de outros tantos a apresentarem morfologia quase idêntica, mas que só se desenvolvem na luz do tubo gastro-intestinal dos piolhos normais, inteiramente saprófitos. Estava o genial investigador na senda verdadedra, começando então a atribuir papel inquestionável de semelhantes germes na produção da doença. Meses depois, no decorrer ainda de 1915, deslocou-se Rocha Lima para a cidade de Wloclavek, na Polônia invadida pelos exércios alemães, reencetando as observações com nôvo material humano. Ganham maior amplitude os seus pontos de vista no tocante à especificidade daqueles microrganismos na produção do tifo exantemático, diante de verificações feitas ulteriormente. Trilhava já agora caminho certo e desbravado nosso saudoso patrício. Em fevereiro de 1916, de posse de dados seguros e convincentes, insere Rocha Lima o seu primeiro comunicado nas páginas dos Archiv für Schiffs-und TropenHygiene (6), sob o título Beobachtungen bei Flecktyphusläusen. Neste artigo descreve tôdas as peripécias que acabo de apon-

(6). - Band 20, n.0 2: 17-31. 
tar. E ganha firmeza a suposição fundamentada de ser o parasito intra-celular descoberto pelo sábio brasileiro o verdadeiro agente do tifo exantemático. Não dorme Rocha Lima sôbre os louros alcançados. Vai a Berlim e no dia 26 de abril de 1916, perante a Kriegspathologische Tagung (Sessão de $\mathrm{Pa}$ tologia de Guerra), apresenta seus originais estudos, condensados em nota intitulada "Zur Aetiologie des Fleckfiebers", inserta no Centralblatt für Allgemeine Pathologie und Pathologische Anatomie (7). Nesta altura, para evitar confusões com múltiplos outros elementos apregoados como germes específicos daquela doença, batiza o seu achado com o nome de Rickettsia prowazeki, em homenagem aos dois grandes pesquisadores vítimas do mal que investigavam, a saber: Ricketts, morto em 1910, e Prowazek, falecido em 1915. Logo a seguir comparece Rocha Lima ao Deutsch Kongress für Innere Medizin, reunido em Varsóvia, nos dias $1 .^{\circ}$ e 2 de maio de 1916. Surge então desagradável incidente. Os organizadores do certame fazem preceder à comunicação de Rocha Lima a apresentação de um trabalho de Töpfer sôbre o mesmo assunto, dando assim prioridade a quem apenas acabava de confirmar as pesquisas originais daquele outro. Rocha Lima irrita-se com êsse menosprêzo e sobretudo por não lhe terem permitido projetar seus diapositivos. Para fins de publicação nos Anais do Congresso é aproveitado apenas um curto resumo de sua comunicação, em contraste com um longo extrato do trabalho de Töpfer. Em sinal de protesto, solicita Rocha Lima, em carta dirigida aos promotores da assembléia, que seu comunicado seja simplesmente enunciado pelo título "como conferência não pronunciada". Daí resulta viva troca de correspondência entre êle e o Prof. W. His, que resolve, então, inserir substancioso apanhado do trabalho de Rocha Lima, invertendo a ordem da publicação, antecedendo-o ao de Töpfer. Procurando desculpar-se de sua primeira atitude e, ao mesmo tempo, acalmar Rocha Lima, faz His certa comparação que não o convence, dizendo ser hábito, nos grandes banquetes, servir-se primeiro o vinho mais nôvo, de qualidade inferior, reservando-se os bons vinhos para a sobremesa. Rocha Lima não se conforma e responde-lhe irònicamente:

"... ich nicht ahnte, dass hierbei die Regedn des Weinschenkens massgebend sein könnten" (8).

(7). - Band XXVII: 45-50, Iena, 1916.

(8). - "Eu jamais poderia pensar que a regra dos vinhos fôsse aplicável ao caso": 
Dessa forma o "Ausspracheanteil" da Rocha Lima incluiuse nas Verhandlung der ausserordentlich Tagung des Deutschen Kongressen für Innere Medizin in Warschau am 1. und 2. Mai 1916: 143-148, Wiesbaden, sob o título genérico "Utber das Fleckfiebers".

Em sucessivas publicações, continua Rocha Lima a alinhar fatos concretos e argumentos científicos em prol da descoberta que the coubera realizar. De 1916 a 1919, nada menos de quatorze artigos em alemão são divulgados nos principais órgãos da imprensa médica germânica, como a Berliner Klinische Wochenschrift, a Münchener Medizinische Wochenschrift, a Deutsche Medizinische Wochenschrift, Die Umchau, etc. Em 1919 , substancioso estudo de conjunto, com 147 páginas, sob a epígrafe Die Ätiologie des Fleckfiebers, assinado por $\mathrm{H}$. da Rocha Lima, é inserto no Ergebnisse !der Allgemeinen Pathologie. und Pathologischen Antomie des Menschen und der Tiere, sob a direção de G. Lubarsch e R. von Ostertag, Wiesbaden, 1919. Depois de apresentar inicialmente vastíssima bibliografia especializada, constante de 649 trabalhos diversos, expõe o cientista patrício tudo quanto de útil foi realizado no campo dos estudos sôbre tifo exantemático, inclusive suas pesquisas originais com a crítica dos trabalhos e opiniões alheias pro e contra suas explanações.

No ano de 1920, depois de prolongada ausência, visita Rocha Lima o Brasil e é recebido solenemente na Academia Nacional de Medicina. Na conferência que teve ensejo de pronunciar nessa ocasião, enumera cautelosamente suas contribuições originais para o conhecimento do tifo exantemático. Embora convencido de estar de posse da verdade, nada afirma categòricamente, mas declara que continua a juntar provas em favor de especificidade da Rickettsia prowazeki, salientando que até aquela data não fôra possível cultivá-la nos meios ordinários, o que dificultava fechar o ciclo de acôrdo com os postulados de Koch, para garantir, de forma absoluta, o papel real na etiologia do morbo.

Pouco depois dessa exposição, são obtidas culturas puras de "Rickettsia" por Wolbach, mediante técnicas delicadas de cultivo em células endoteliais in vitro, e mais tarde por $H$. R. Cox, em 1938, mercê de inoculação em ovos embrionados de galinha, desenvolvendo-se o parasito exuberantemente nas células da membrana vitelina.

Além do estudo morfológico e biológico da espécie por êle batizada em primeiro lugar, e de outros tipos do mesmo gênero, 
tentou Rocha Lima obter vacinas e sôros com parasitos desenvolvidos nas células epiteliais do tubo digestivo dos piolhos, mantendo para isso verdadeiras "culturas vivas" de germes.

Em 1950, Rocha Lima, que já regressara definitivamente ao Brasil desde 1928, para trabalhar no Instituto Biológico de São Paulo, cuja direção geral efetiva assumiu em 1933 e nela permaneceu durante mais de 15 anos, comparecia perante 0 $\checkmark$ Congresso Internacional de Microbiologia, reunido no Rio de Janeiro, e numa conferência em que deixava transparecer profundo ressentimento diante da injustificável atitude de certos meios científicos face às suas contribuições básicas para o esclarecimento da etiologia do tifo exantemático, protestava veementemente contra a versão lançada, sobretudo na América do Norte, de que êle nada mais fizera do que repetir os ensaios de Ricketts e Wilder, confirmando-os. Mostrou, então, que nenhuma repercussão tiveram tais estudos, nem na própria América do Norte, por ocasião de sua divulgação. Ainda mais. No espaço compreendido entre a publicação firmada por aquêles dois cientistas (1910) e o ano em que descreveu e caracterizou a Rickettsia prowazeki (1916), inúmeros germes foram apresentados por diferentes autores (Fuerth, 1912; Klodnisky, 1913; Mueller, 1914; Arnheim, 1915; Proecher, 1915; Petruchky, 1916; Penfold, 1916; Csernel, 1916; Weil-Felix, 1916), como agentes etiológicos do tifo exantemático, o que denota a insuficiência da demonstração de Ricketts e Wilder. Ao contrário disso, após a apresentação fartamente conclusiva da Rickettsia prowazeki, muito embora tivesse que desenvolver cerrada argumentação contra as objeções enunciadas, nenhum outro germe surgiu com a finalidade de desbancar o verdadeiro agente do tifo exantemático, a supracitada R. prowazeki, apeando-a do pedestal científico, hoje perfeitamente consolidado em todo o mundo.

Numa declaração profética, assim se exprimiu então Rocha Lima:

"Um melhor conhecimento desta (descuidada parte histórica do tifo exantemático) poderia porém servir talvez como um aviso da experiência aos que se iniciam no campo da pesquisa, mostrando a necessidade de defenderem insistentemente em lingua predominante a parte que realmente lhes caiba do alcançado progresso no campo da Ciência, e poderá além disso interessar a algum curioso de detalhes da história da Medicina ou então a um estudioso patrício, que, imitando os cientistas dos paises à frente da nossa civilização, prefira não silenciar ou de- 
preciar, mas sim apurar, registrar e talvez mesmo defender o que no campo destas conquistas possa caber a um seu compatriota, isto é, a seu pais".

Aqui estamos, pois, eu e o Prof. Otto G. Bier, para repor a versão científica correta quanto ao valor real das demonstraçōes do grande Prof. $\mathrm{H}$. da Rocha Lima, glória da ciência universal, criador de um capítulo nôvo no mundo da microbiologia, o das rickettsioses, e autor de inúmeros e valiosos trabalhos originais sôbre a febre amarela, a verruga peruviana, a blastomicose, o carbúnculo sintomático, a peste bubônica, etc.

TRABALHOS DO PROF. H. DA ROCHA LIMA SOBRE A "RICKETTSIA PROWAZEKI" E OUTRAS "RICKETTSIAS" E "RICKETTSIOSES".

1). - "Beobachtungen bei Flektyphusläusen" (1916), Archiv für Schiffsund Tropen-Hygiene, Band 20, Nr. 2: 17-31.

2). - "Zur Ätiologie des Fleckfiebers" (1916), Centralblatt für Allgemeine Pathologie und Pathologische Anatomie, Beiheft zu Band XXVII: 45-50 (Kriegspathologische Tagung in Berlin am 26. und 27. April 1916).

3). - "Utber das Fleckfieber" (1916) Verhandlungen der ausserordentlichen Tagung des Deutschen Kongresses für Innere Medizin in Warschau, am 1. and 2. Mai 1916, Ausspracheanteil von Dr. Rocha Lima (Hamburg): 143-148.

4). - "Zur Aetiologie des Fleckfiebers" (Vorläufige Mitteilung) (1916), Berliner Klinische Wochenschrift, Nr. 21, 53. Jahrgang, 22. Mai 1916.

5). - "Untersuchungen über Fleckfieber" (1916), Münchener Medizinische Wochenschrift, $\mathrm{Nr}$. 39, 63, Jahrgang, 26. September 1916

6). - "Zur Aetiologie des Fleckfiebers" (1916), (Bemerkungen zu den in Nr. 38 und 41 dieser Wochenschrift erschienenen Aufsātzen von Toepfer und Schüssler) Deutsche Medizinische Wochenschrift, Nr. 44, 42. Jahrgang, 2. November 1916.

7). - "Ergebnisse der Fleckfieberforschung" (1916) (Vortrag, gehalten vor der Senkenbergischen Naturforschenden Gesellschaft in Frankfurt a. M. am 4. Nov. 1916. Feldärztliche Blätter der k. u. k. 2. Armee (Nr. 21, 1916).

8). - "Die Ursache des Fleckfiebers" (1916), Die Umschau, Frankfurt a. M., XX. Jahrgang, Nr. 51, 1916.

9). - "Zum Nachweis der Rickettsia Prowazeki bei Fleckfieberkranken" (1917), Münchener Medizinịsche Wochenschrift, Nr. 1, 2. Januar 1917 - Feldärztliche Beilage Nr. 1.

10). - "Zür Aetiologie des Fleckfiebers" (1917) (Erwiderung auf die Ausführungen Toepfers in Nr. 49), Deutsche Medizinische Wochenschrift, Nr. 2, 43. Jahrgang, 11. Januar 1917. 
11). - "Klinik und Aetiologie des sogen. "Wolhynische Fiebers" (Werner-Hissche Krankheit) Fritz Munk colab. (1917), I Klinischer Teil, Münchener Medizinische Wochenschrift, $\mathrm{Nr}$. 42, 64. Jahrgang, 16. Oktober 1917.

12). - "Klinik und Aetiologie des sogen. "Wolhynische Fiebers" (Werner-Hissche Krankheit) Fritz Munk colab. (1917), I Ergebnis der atiologischen Untersuchungen und deren Bezie(1919), Bemerkbigen zur Ricketsiafrage, Deutsche Medizivista Médica de Hamburgo, Ano I, Nr. 5, Agosto 1920.

13). - "Die Schutzimpfung gegen Fleckfieber" (1917), Medizinische Klinik, Nr. 43, 1917.

14). - "Schutzimpfungversuche gegen Fleckfieber" (1918), Münchener Medizinische Wochenschrift, Nr. 52, 65. Jahrgang, 24. Dezember 1018.

15). - "Die Atiologie des Fleckfiebers" (1919) Ergebnisse der Allgemeinen Pathologie und Pathologischen Anatomie des Menschen und der Tiere, herausgegeben von $O$. Lubarsch und $R$. von Ostertag, 1919: 159-306.

16). - "Uber die Átiologie des Fleckfiebers" (1919) Berliner Klinik, Heft 325, 29. Jahrgang, Juli 1919.

17). - "Die Uebertragung des Rückfallfiebers und des Fleckfiebers" (1919), Bemerkungen zur Rickettsiafrage, Deutsche Medizische Wochenschrift, Nr. 27, 45. Jahrgang. 3. Juli 1919.

18) . - "Pesquisas sôbre o tifo exantemático durante a guerra mundial" (1920), Boletim da Academia Nacional de Medicina do Rio de Janeiro, 91.० Ano, n. ${ }^{\circ} 11$, Sessäo de 17 de junho de 1920: 228-239.

19). - "Introducción en el estudio de los clamidozoarios" (1920), Revista Médica de Hamburgo, Ano I, Nr. 5, Agôsto 1920.

20). - "Notas sôbre o micróbio do tifo exantemático" (1921), Revista Médica de Hamburgo, Ano II, Nr. 1, Enero 1921: 20-23 e Nr. 2, Febrero 1921: 43-45.

21). - "Methoden zur Untersuchung von Läusen als Infektionsträger" (1925), H. Sikora colab., Handbuch der biologischen Arbeitsmethoden, herausgegeben von Dr. Emil Abderhalden, Berlin-Wien, 1925: 769-814.

22). - "Rickettsien" (1930), Handbuch der pathogenen Mikroorganismen, herausgegeben von $W$. Kolle, $R$. Kraus und $P$. Uhlenhut, Jena-Berlin-Wien, Band VIII. Lig. 45, 1930: 13471386 .

23). - "Rickettsia Prowazeki" (Sua descoberta e caracterização constituindo um nôvo grupo de microrganismos), Revista Braslleira de Medicina, Vol. VIII, N.o 5, maio de 1951.

Santos, novembro de 1965. 